\title{
Systemic and Inhaled Corticosteroids, with or without Beta Agonists, as Adjuvant Therapy in Community Acquired Pneumonia
}

\author{
Scott A. Helgeson ${ }^{1}$, Joseph E. Levitt ${ }^{2}$, Emir Festic ${ }^{1}$ \\ ${ }^{1}$ Pulmonary and Critical Care Medicine, Mayo Clinic, Jacksonville, FL, USA, ${ }^{2}$ Pulmonary and Critical Care Medicine, Stanford \\ University, Stanford, CA, USA \\ Correspondence: festic.emir@mayo.edu; Tel.: + 1904953 6278; Fax.: + 19049532082
}

Received: 20 January 2020; Accepted: 22 April 2020

\begin{abstract}
The aim is to provide a narrative review of the role of corticosteroids, with and without inhaled beta agonist, in communityacquired pneumonia. Community and health-care associated pneumonia remain leading causes of morbidity and mortality despite appropriate antibiotic therapy. The pneumonia-associated adverse outcomes are not only related to the infectious organism, but also to a dysfunctional host-immune response resulting in overwhelming inflammation. Use of systemic corticosteroids as adjuvant therapy in pneumonia remains controversial. Multiple randomized clinical trials evaluating corticosteroids in patients with community acquired pneumonia have found discrepant results in terms of benefits and adverse effects. Inhaled delivery of corticosteroids offer the potential advantage of providing therapeutic benefits directly to the lung, with minimal to no adverse systemic effects. Conclusion. Although meta-analyses suggest potential benefits in a select group of patients with more severe pneumonia, the ideal timing, dose, route of delivery, duration, and patient selection remain to be established. A smaller body of literature suggests benefit of inhaled corticosteroids, with or without inhaled beta agonists, but future large scale clinical trials are needed to establish clinical benefit with inhaled delivery.
\end{abstract}

Key Words: Pneumonia - Corticosteroids • Beta-Agonists.

\section{Introduction}

Community-acquired pneumonia (CAP) is the leading infectious cause of hospitalization and death in the United States costing more than 10 billion dollars in $2015(1,2)$. CAP and hospital associated pneumonia cause roughly $50 \%$ of the cases of acute respiratory distress syndrome (ARDS) resulting in a high mortality rate in patients requiring admission to the intensive care unit (ICU) (3-5). The mortality rate from pneumonia has not decreased substantially since initial improvement with widespread adoption of antibiotic therapy as standard of care in the late 1900's (6). The high mortality rate of pneumonia may be due to the broad range of infectious etiologies and clinically unidentified pathogens (7). This high mortality may also involve host- specific factors including comorbidities and either an inadequate or overzealous host response (8).

Once a pathogen enters the host causing pneumonia, there is subsequent release of inflammatory cytokines that activate the vascular endothelium and recruit neutrophils to help contain the local infection (8). This host response also disrupts the normally preserved barrier between the alveolar (external environment) and vascular (internal systemic environment) compartments $(9,10)$. This barrier loss causes alveoli to flood with protein-rich edema fluid, leading to the loss of lung compliance, hypoxemia, acute lung injury, and ultimately acute respiratory failure (11). In addition, activation of vascular endothelium can promote a marked systemic inflammatory response syndrome (SIRS) leading to shock and multiorgan dysfunction, while increased vascular perme- 
ability can promote dissemination of bacteremia. There has been ample research into adjuvant oral, intravenous, and inhaled anti-inflammatory and/ or immunomodulating therapies to combat this dysfunctional host response in an effort to improve mortality in patients with pneumonia. Despite the current state of evidence, it remains unclear which patient subgroups are most likely to benefit from adjuvant therapies.

This review will summarize the data on corticosteroids, systemic and inhaled (with and without inhaled beta-agonists) to show their potential roles.

\section{Methods}

For the literature search, we used PubMed MESH search headings "steroids" and "pneumonia" and included studies that have been published in the English language since 1990 . We sequentially reviewed: Preclinical studies, human randomized controlled trials and meta-analyses of clinical trial data. We separately reported results of the studies using systemic versus inhaled steroids (with or without beta agonists), and included observational studies on role of systemic steroids in viral pneumonia.

\section{Results}

\section{Preclinical Studies Suggesting Benefits of Corticosteroid Use in Pneumonia}

Multiple preclinical studies have shown beneficial effects of systemic corticosteroids on the dysfunctional host response caused by pneumonia. One in vitro study showed suppressed bacterial replication in the presence of methylprednisolone when human monocytes were infected with different bacteria (12). Inflammatory markers including TNF- $\alpha$, IL- $1 \beta$, and IL- 6 were also reduced after treatment with methylprednisolone. In a mice model, Li et al. intratracheally introduced Escherichia coli and then either treated with hydrocortisone or placebo and found a decrease in serum levels of IL- 6 , INF- $\gamma$, and nitric oxide in the mice that were treated with hydrocortisone (13). In a separate model of piglets bronchoscopically inoc- ulated with Pseudomonas aeruginosa, Sibila et al. compared the effects of ciprofloxacin alone versus ciprofloxacin plus methylprednisolone (14). Proinflammatory cytokines and bacterial cell counts were both decreased in both the bronchoalveolar lavage (BAL) and serum in the group treated with corticosteroids.

\section{Clinical Studies of Systemic Corticosteroids in Pneumonia}

\section{Randomized Controlled Trials}

The following review is not intended to be a comprehensive one, but will highlight studies with important contributions to the current state of the evidence. A more comprehensive listing and brief descriptions of prospective trials in humans is provided in Table 1. For this review, a PubMed MESH search using headings "steroids" and "pneumonia" and including only randomized clinical trials in humans and in the English language was performed.

Two early preliminary studies found discordant results. The first by Marik et al. in 1993, randomized 30 patients with three or more British Thoracic Society criteria of severe pneumonia to receive $10 \mathrm{mg} / \mathrm{kg}$ of hydrocortisone or placebo and found no difference in the intensive care unit (ICU) length of stay (LOS) in the treatment $(4.3 \pm 3.8$ days) versus control group (4.6 \pm 5.9 days) (15). Subsequently, Monton et al., showed a decrease in systemic and lung inflammatory responses by measuring TNF- $\alpha$, IL- $1 \beta$, IL- 6 , and c-reactive protein (CRP) levels in the serum and BAL fluid in mechanically ventilated patients receiving a large intravenous dose of $677 \pm 508 \mathrm{mg}$ methylprednisolone for $9 \pm 7$ days (16).

Confalonieri et al. showed improved clinical outcomes in 46 CAP patients randomized to hydrocortisone with a $200 \mathrm{mg}$ intravenous bolus followed by an infusion at a rate of $10 \mathrm{mg} /$ hour for 7 days versus placebo (17). The treatment group had a 60 -day mortality of 0 vs. $8(38 \%)(\mathrm{P}=0.009)$ and a hospital LOS of 13 days (range, 10-53 days) vs. 21 days (range, 3-72 days) $(\mathrm{P}=0.03)$ despite hav- 
Table 1. Summary of Prospective Trials on Systemic Corticosteroids in Pneumonia

\begin{tabular}{|c|c|c|c|c|c|c|c|}
\hline Study & $\begin{array}{l}\text { Target } \\
\text { Population }\end{array}$ & $\begin{array}{l}\text { Number } \\
\text { of Patients } \\
\text { (Control vs } \\
\text { Intervention) }\end{array}$ & Intervention & $\begin{array}{l}\text { Hospital } \\
\text { Mortality } \\
\text { (Control vs } \\
\text { Intervention) }\end{array}$ & $\begin{array}{l}\text { 30-Day } \\
\text { Mortality } \\
\text { (Control vs } \\
\text { Intervention) }\end{array}$ & $\begin{array}{l}\text { Hospital LOS } \\
\text { (Control vs } \\
\text { Intervention) }\end{array}$ & $\begin{array}{l}\text { Time to Clinical } \\
\text { Stability (Control } \\
\text { vs Intervention) }\end{array}$ \\
\hline $\begin{array}{l}\text { Marik et al. } \\
\text { (15) }\end{array}$ & $\begin{array}{l}\text { Adults } \\
\text { hospitalized } \\
\text { with CAP to the } \\
\text { ICU }\end{array}$ & 16 vs 14 & $\begin{array}{l}10 \mathrm{mg} / \mathrm{kg} \text { of } \\
\text { hydrocortisone once }\end{array}$ & $\begin{array}{l}25 \% \text { vs } 7.1 \% \\
\text { (NS) }\end{array}$ & Not assessed & 4.6 vs 4.3 & Not assessed \\
\hline $\begin{array}{l}\text { Monton et } \\
\text { al. (16) }\end{array}$ & $\begin{array}{l}\text { Adults } \\
\text { hospitalizedwith } \\
\text { CAP requiring } \\
\text { mechanical } \\
\text { ventilation }\end{array}$ & 9 vs 11 & $\begin{array}{l}677 \pm 508 \mathrm{mg} \mathrm{IV} \\
\text { methylprednisolone } \\
\text { for } 9 \pm 7 \text { days }\end{array}$ & $\begin{array}{l}67 \% \text { vs } 36 \% \\
(P=0.37)\end{array}$ & Not assessed & Not assessed & Not assessed \\
\hline $\begin{array}{l}\text { Confalonieri } \\
\text { et al. (17) }\end{array}$ & $\begin{array}{l}\text { Adults } \\
\text { hospitalized } \\
\text { with CAP }\end{array}$ & 24 vs 24 & $\begin{array}{l}\text { Hydrocortisone } 200 \\
\mathrm{mg} \text { bolus followed } \\
\text { by } 10 \mathrm{mg} / \text { hour } \\
\text { infusion for } 7 \text { days }\end{array}$ & $\begin{array}{l}30 \% \text { vs } 0 \% \\
(P=0.009)\end{array}$ & $\begin{array}{l}38 \% \text { vs } 0 \% \\
(P=0.001)\end{array}$ & $\begin{array}{l}21 \text { vs } 13 \text { days } \\
(P=0.03)\end{array}$ & Not assessed \\
\hline $\begin{array}{l}\text { Fernandez } \\
\text { et al. (18) }\end{array}$ & $\begin{array}{l}\text { Adults } \\
\text { hospitalized } \\
\text { with CAP }\end{array}$ & 28 vs 28 & $\begin{array}{l}200 \text { mg bolus of } \\
\text { methylpredniso- } \\
\text { lone followed by } \\
\text { infusion for } 9 \text { days }\end{array}$ & $\begin{array}{l}3.6 \% \text { vs } 3.6 \% \\
\text { (NS) }\end{array}$ & Not assessed & $\begin{array}{l}12 \text { vs } 10 \text { days } \\
\text { (NS) }\end{array}$ & $\begin{array}{l}7 \text { vs } 5 \text { days } \\
(P=0.02)\end{array}$ \\
\hline $\begin{array}{l}\text { Meijvis et al. } \\
\text { (19) }\end{array}$ & $\begin{array}{l}\text { Adults } \\
\text { hospitalized } \\
\text { with CAP }\end{array}$ & 153 vs 151 & $\begin{array}{l}5 \text { mg IV } \\
\text { dexamethasone } \\
\text { daily for } 4 \text { days }\end{array}$ & $\begin{array}{l}5 \% \text { vs } 5 \% \\
(P=0.98)\end{array}$ & $\begin{array}{l}7 \% \text { vs } 6 \% \\
(P=0.68)\end{array}$ & $\begin{array}{l}7.5 \text { vs } \\
6.5 \text { days } \\
(P=0.048)\end{array}$ & Not assessed \\
\hline $\begin{array}{l}\text { Blum et al. } \\
\text { (20) }\end{array}$ & $\begin{array}{l}\text { Adults } \\
\text { hospitalized } \\
\text { with CAP }\end{array}$ & 393 vs 392 & $\begin{array}{l}50 \mathrm{mg} \text { oral } \\
\text { prednisone for } 7 \\
\text { days }\end{array}$ & Not assessed & $2 \%$ vs $1 \%$ & $\begin{array}{l}7 \text { vs } 6 \text { days } \\
(P=0.01)\end{array}$ & $\begin{array}{l}4.4 \text { vs } 3 \text { days } \\
(P=0.01)\end{array}$ \\
\hline $\begin{array}{l}\text { Torres et al. } \\
\text { (21) }\end{array}$ & $\begin{array}{l}\text { Adults } \\
\text { hospitalized } \\
\text { with CAP and } \\
\text { CRP }>150 \mathrm{mg} / \mathrm{L}\end{array}$ & 59 vs 61 & $\begin{array}{l}0.5 \mathrm{mg} / \mathrm{kg} \text { per } \\
12 \text { hours of IV } \\
\text { methylprednisolone } \\
\text { for } 5 \text { days }\end{array}$ & $\begin{array}{l}15 \% \text { vs } 10 \% \\
(P=0.37)\end{array}$ & Not assessed & $\begin{array}{l}10.5 \text { vs } 11 \\
\text { days }(P=0.83)\end{array}$ & $\begin{array}{l}5 \text { vs } 4 \text { days } \\
(P=0.28)\end{array}$ \\
\hline $\begin{array}{l}\text { Snijders et } \\
\text { al. (22) }\end{array}$ & $\begin{array}{l}\text { Adults } \\
\text { hospitalized } \\
\text { with CAP }\end{array}$ & 109 vs 104 & $\begin{array}{l}40 \mathrm{mg} \text { of oral or IV } \\
\text { prednisolone daily } \\
\text { for } 7 \text { days }\end{array}$ & Not assessed & $\begin{array}{l}5.5 \% \text { vs } 5.8 \% \\
(P=0.93)\end{array}$ & $\begin{array}{l}10.6 \text { vs } 10 \\
\text { days }(P=0.16)\end{array}$ & $\begin{array}{l}\text { HR 1.14; } \\
95 \% \mathrm{Cl} 0.82-1.59 \\
(\mathrm{P}=0.44)\end{array}$ \\
\hline
\end{tabular}

LOS=Length of stay; ICU=Intensive care unit; $C A P=C o m m u n i t y$ acquired pneumonia; $C R P=C$-reactive protein; IV=Intravenous; HR=Hazard ratio; $N S=N o t$ significant.

ing higher CRP levels (mean, 55 [range, 14-349] vs. 29 [6-200], $\mathrm{P}=0.04$ ) and a lower $\mathrm{P} / \mathrm{F}$ ratios (the ratio of the partial pressure of arterial oxygen to fractional inspired oxygen) (mean \pm SD, $141 \pm 49$ vs. $178 \pm 58, \mathrm{P}=0.03$ ) at study enrollment.

Larger trials, including patients with many different pneumonia severities, suggest that the antiinflammatory properties of adjuvant corticosteroids may blunt the host inflammatory response and shorten time to clinical stability and hospital length of stay. In a single-center study, Meijvis et al. randomized 304 patients with a wide range of Pneumonia Severity Index (PSI) risk classes to receive $5 \mathrm{mg}$ of intravenous dexamethasone daily or placebo (19). LOS was reduced in the steroid group by 1 day ( 6.5 vs. $7.5 ; \mathrm{P}=0.048)$. Similarly, in the largest multicenter study to date, Blum et al. randomized nearly 800 patients in the moderate risk class (PSI II-IV) to $50 \mathrm{mg}$ of prednisone or placebo for 7 days (20). In the steroid treated patients, there was a reduction in time to clinical stability ( 3.0 vs. 4.4 days; HR 1.33; 95\% CI, 1.15-1.50; $\mathrm{P}<0.001$ ), and there was a 1 day reduction in hospital LOS (6 vs. 7 days, $\mathrm{P}=0.01$ ). However, neither study found an improvement in mortality and rates of hyperglycemia were significantly increased in both trials (19, 20). Snijders et al. randomized 213 patients with mild to moderate CAP to receive either $40 \mathrm{mg}$ prednisolone daily or placebo for 7 days and found no difference in the primary endpoint of clinical cure 
(2). Interestingly, more steroid-treated patients had worsening of symptoms after 7 days (OR 2.36; 95\% $\mathrm{CI}, 1.05-5.31 ; \mathrm{P}=0.04)$, suggesting initial blunting of the SIRS response may have led to a delay in negative sequelae in this lower-risk population. However, CRP levels were higher in the treatment group (suggesting that these patients may have been more severely ill at baseline) and this appears to be an isolated finding, limiting confidence in this interpretation. Still, it is reasonable that the potential benefits of adjuvant corticosteroids are more limited in less severely-ill patients, thus increasing the risk for potential harms due to hyperglycemia and delayed immunosuppression.

In an attempt to study a more homogenous patient population with more potential to benefit from systemic steroids, Torres et al. performed a multicenter trial of patients with severe CAP and a strong host inflammatory response signified by high baseline CRP level (>150mg/L) (21). Severity of CAP was defined based on the modified American Thoracic Society criteria or a PSI V (3). Patients were randomized to receive $0.5 \mathrm{mg} / \mathrm{kg}$ of intravenous methylprednisolone every 12 hours or placebo for 5 days. Treatment failure-defined as development of shock, the need for mechanical ventilation, death, or radiographic progression $(\geq 50 \%$ increase in size of infiltrate)-was significantly reduced in the steroid group (OR 0.34; 95\% CI, 0.14-0.87; $\mathrm{P}=0.020$ ). However, the overall improvement in the combined endpoint was driven mainly by the lack of late radiographic progression in the steroid group. In direct contrast to Sneijders et al., a posthoc analysis found no difference in early $(<72 \mathrm{~h})$ treatment failures, but late treatment failure $(>72 \mathrm{~h})$ was reduced in the steroid group. Time to clinical stability, ICU and hospital LOS, and in-hospital mortality were not different between the groups, limiting definitive interpretation of trial results for these more clinically relevant endpoints. Finally, it took 8 years to recruit 120 patients at 3 hospitals, potentially limiting the generalizability of these more restrictive inclusion criteria.

In an attempt to make treatment more homogenous, Lloyd et al. performed a blinded randomized trial of 816 patients with CAP who were treated with a pneumonia bundle that included $50 \mathrm{mg}$ per day of prednisolone acetate or equivalent (4). There was no difference in hospital length of stay (mean ratio of 0.95 ; 95\% CI, 0.57-1.59), 90 day mortality ( $0.89 ; 95 \% \mathrm{CI}, 0.48-1.63)$, and 90 day readmission rate (1.18; 95\% CI, $0.69-2)$. This study included all patients with CAP and did not stratify by severity which about $50 \%$ of the patients in this study would have met criteria for severe CAP.

Combined, these trials suggest a possible decrease in hospital LOS in patients with severe CAP treated with corticosteroids, but with increased rates of hyperglycemia. It is possible that the associated hyperglycemia may partially explain the lack of mortality benefit as observational studies have found an increased mortality in CAP patients with hyperglycemia (25-27). However, the clinical relevance of increased hyperglycemia due to systemic steroids is uncertain. A large population based study of 327,452 patients that received a short course of steroids (median 6 days [interquartile range 6-12 days]) showed increased incidence of sepsis (incidence rate ratio (IRR) 5.3; 95\% CI, 3.87.41), venous thromboembolism (IRR 3.33; 95\% CI, 2.78-3.99), and for fractures (IRR 1.87; 95\% CI, 1.69-2.07). This shows that even short courses of steroids may have potentially serious complications (28). More importantly, individual studies of heterogeneous populations lacking enrichment for patients most likely to benefit from adjuvant corticosteroid therapy have been likely underpowered to detect mortality benefit in low-risk patients (29). Based on these studies, however, it appears that the more severely ill patients with CAP may derive benefit with adjuvant corticosteroids.

\section{Meta-Analyses of Clinical Trial Data}

A PubMed MESH search using headings "metaanalysis", "steroids", and "pneumonia", found six meta-analyses all showing some benefit in clinical outcomes (30-36). A meta-analysis by Siemieniuk et al. of twelve trials and 1,974 patients provided a more nuanced interpretation of the discordant results seen in individual studies. While there was a nonsignificant reduction in all-cause mortality 
(RR 0.67; 95\% CI, 0.45-1.01), subgroup analysis of patients with "severe" CAP showed a significant improvement in mortality (RR 0.39; 95\% CI, 0.2-0.77; $\mathrm{P}=0.01$ ) (30). There was also a significant reduction in the need for mechanical ventilation and development of ARDS among patients treated with steroids. However, the overall methodological strength of the included studies was considered to be low and one of the included trials, by Confalonieri et al. demonstrated remarkable benefit of corticosteroids towards mortality, which was considered to be an outlier to the other RCTs (17). Even after the exclusion of this trial's data, there was a benefit of systemic corticosteroids towards all-cause mortality in patients with severe CAP.

A more recent meta-analysis addressed inherent heterogeneity by performing an individual data analysis including patients from 6 RCTs while excluding 5 smaller and 2 larger trials from 1970's (1). Overall, there was no difference in mortality either with or without the Confalonieri trial. However, time to both clinical stability and hospital LOS were reduced by approximately 1 day in patients receiving corticosteroids, but so were the rates of hyperglycemia and CAP-related re-hospitalizations. No significant effect modifications were found, although trends existed for greater effects in severe pneumonia.

Stern et al. included 17 RCTs (including 4 RCT's enrolling children) in their meta-analysis (2). Corticosteroid therapy reduced overall mortality in adults only with severe pneumonia (RR 0.58; 95\% CI, 0.40-0.84). Corticosteroids also improved early clinical failure (death from any cause, radiographic progression, or clinical instability at days 5 to 8 ) in all patients regardless of pneumonia severity. Corticosteroid therapy was associated with hyperglycemia, but there were no differences for other adverse effects or secondary infections. This review included smaller and "lower quality" studies (11 of the 17 trials were single center, 9 were open-label, and 14 were assessed as highrisk for selective reporting bias due to inadequate blinding of participants and personnel) and it is unclear whether inclusion of these provided more precision for the true treatment effect.

\section{Corticosteroids in Viral Pneumonia}

To date, there are no RCTs specifically investigating corticosteroids in viral pneumonia. A recent Cochrane review could only identify low quality observational studies addressing adjuvant corticosteroids in influenza pneumonia and suggested a three-times increased odds of mortality and an increase in hospital-acquired infections in the steroid treated patients. The differences in severity of illness could not be adequately addressed and the data was judged to be of very low methodological strength (37). Recently, Moreno et al. performed a secondary analysis of an earlier multicenter observational study to determine the effect of corticosteroids in severe influenza pneumonia (38). This study included 1846 patients with influenza pneumonia admitted to the ICU and treated with relatively higher doses of corticosteroids (median daily dose equivalent to $80 \mathrm{mg}$ of methylprednisolone) for a mean duration of 7 days. After a propensity-matched analysis, corticosteroid use was associated with an increase in ICU mortality (HR 1.32; 95\% CI, 1.08-1.60; $\mathrm{P}<0.006$ ) (38). Another meta-analysis using ten trials with 6,548 patients showed that corticosteroids resulted in a higher mortality (RR 1.75; 95\% CI, 1.30-2.36; $\mathrm{P}=0.0002$ ), longer ICU LOS (mean difference 2.14 days; 95\% CI, 1.17-3.10; $\mathrm{P}<0.0001)$, and a higher rate of secondary infection (RR 1.98; 95\% CI, 1.04-3.78; $\mathrm{P}=0.04)$ when compared to placebo (39).

There is a biologic explanation for these results for corticosteroids in viral pneumonia. Corticosteroids may provide benefit for bacterial infections by preventing negative systemic sequelae of a robust SIRS response while still allowing for effective bacterial clearance with potent antibiotics. On the other hand, lacking similarly potent antiviral therapy, a blunted host response may allow greater viral replication and dissemination resulting in greater systemic organ involvement and late-onset complications when treating viral pneumonia, such as influenza. The increased mortality could be related to an increase in secondary bacterial infections when these patients are given corticosteroids. These, plus other mechanisms could all result in 
the increased mortality seen in adjuvant corticosteroid use in influenza pneumonia. The increased mortality observed in populations of patients with viral pneumonia could have implications in the previous studies of adjuvant corticosteroids as viral vs. bacterial pneumonia were not differentiated in the majority of the studies (although, the Torres trial (21) excluded patients with influenza). Moreover, the commonly used rapid influenza diagnostic test using an immunoassay has lower sensitivity when compared to PCR (40), allowing for misclassification of patients being treated for bacterial pneumonia and possibly increasing complications from adjuvant corticosteroids.

\section{Studies with Inhaled Delivery of Corticosteroids}

There is a theoretical concern that systemic corticosteroids may have variable anti-inflammatory effects in the alveolar compartment, and that inhaled delivery of corticosteroids may provide more effective anti-inflammatory benefits directly to the target organ while limiting negative systemic effects, such as, hyperglycemia and immunosuppression (Figure 1). A recent study showed that after instillation of endotoxin into the lungs of healthy patients, 40mg of intravenous dexamethasone markedly reduced anti-inflammatory markers in the peripheral blood, while only slightly affecting those in BAL fluid (41). As both systemic and inhaled corticosteroids affect the same inflammatory mediators, it is plausible that inhaled delivery would result in the same anti-inflammatory effects in the lungs without the adverse effects, compared to systemic delivery. This benefit needs to be contrasted with the long-term administration of inhaled steroids for chronic obstructive pulmonary diseases, where a higher incidence of pneumonia requiring hospitalization has been observed, but without an increase in mortality $(42,43)$.

Multiple studies involving experimental models of lung injury and/or pneumonia have demonstrated amelioration of inflammation, histo-

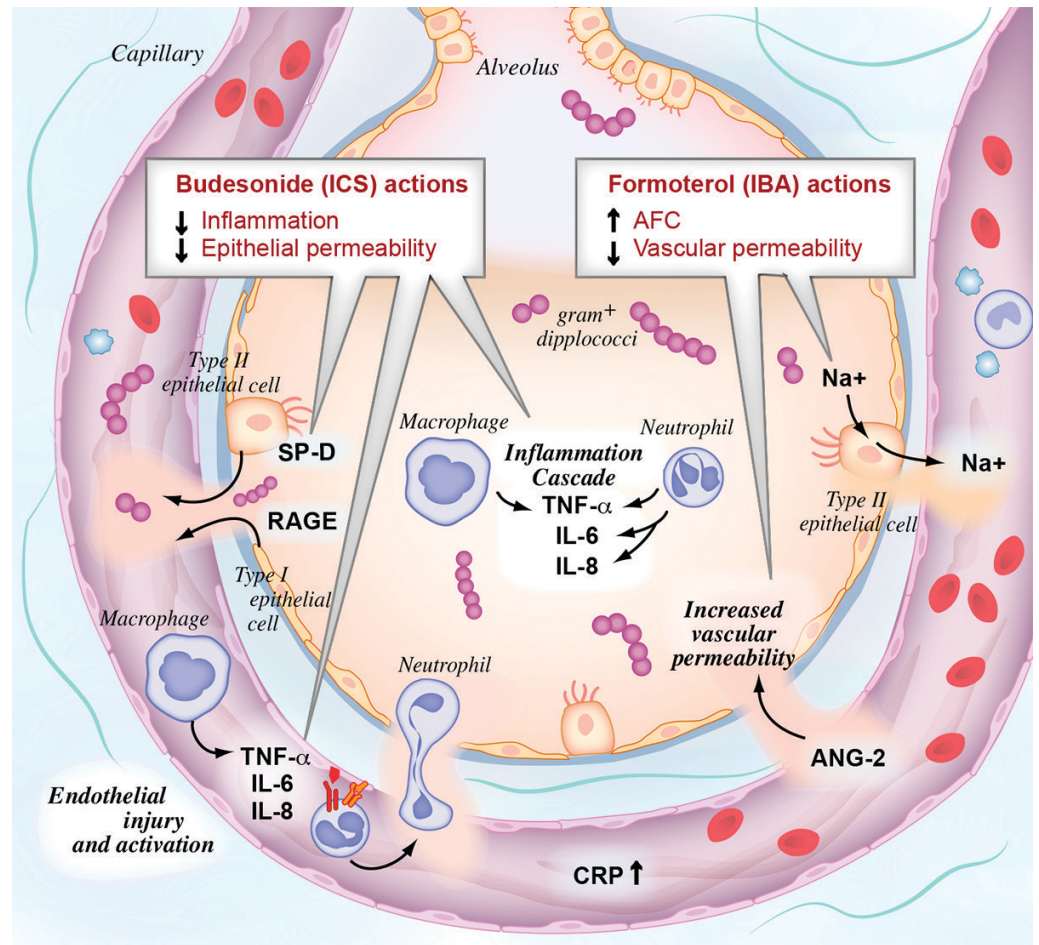

Legends: Key pathways in progression of lung injury. Infection causes neutrophils to release inflammatory cytokines IL-6, IL-8, and TNF- $a$ which in turn causes epithelial injury (marked by increased levels of RAGE and SP-D) and vascular permeability (marked by increased ANG-2). There is potential for inhaled corticosteroids (ICS) to reduce this inflammatory response and limit epithelial permeability while inhaled beta agonists (IBA) could increase alveolar fluid clearance (AFC) and preserve vascular barrier function.

Figure 1. ICS=Inhaled corticosteroid; IBA=Inhaled beta-agonist; SP-D=Surfactant protein-D; RAGE=Receptor for advanced glycation endproducts; TNF=Tumor necrosis facotr; IL=Interleukin; Na=Sodium; CRP=C-reactive protein; ANG2=Angiotensin 2; AFC=Alveolar fluid clearance. 
logic injury, and derangement in oxygenation, hemodynamics, and lung mechanics when treated with inhaled corticosteroids compared to placebo. Walther et al. studied effects of nebulized beclomethasone starting 30-minutes after infusion of live Staphylococcus aureus in mechanically ventilated pigs (44). Oxygenation, hemodynamics, and lung mechanics were better maintained in pigs receiving nebulized beclomethasone after onset of sepsis relative to placebo. Forsgreen et al. studied effects of prophylactic treatment with an aerosolized corticosteroid in a pig model of early ARDS induced by Escherichia coli (45). Pretreatment with aerosolized corticosteroids, either 15-minutes or 2-hours before the start of an endotoxin infusion, improved lung mechanics and hemodynamics relative to placebo. Jansson et al. also investigated the effect of pretreatment with aerosolized corticosteroids on lung injury and inflammation following varying doses of intratracheally instilled lipopolysaccharide (LPS) (46). Pretreatment with aerosolized budesonide decreased the production of inflammatory cytokines TNF- $\alpha$, IL$1 \beta$, and monocyte chemoattractive protein- 1 after challenge with both low and high concentrations of LPS. Greater differences in pulmonary edema and development of ALI were seen at higher LPS concentrations suggesting that therapeutic effects of aerosolized budesonide were greater with more severe disease.

Timing of administration of therapy has varied across multiple studies. Wang et al. examined the effect of varying the time between injury and treatment with nebulized corticosteroids on lung injury in animal models (47). Nebulized budesonide was given immediately, 30 , or 60 -minutes following chlorine gas exposure. The mean arterial oxygen tension in animals treated immediately and 30-minutes post-delivery of budesonide was significantly higher than in controls or animals treated 60-minutes post-delivery. The recovery of lung compliance was enhanced and the pulmonary wet-to-dry weight ratio was lower in all three budesonide groups relative to controls, suggesting that while earlier is better, benefit may still occur with delayed treatment. Despite inherent hetero- geneity, the above studies demonstrate relatively consistent beneficial effects of inhaled corticosteroids in animal models of lung injury caused by either inhaled or systemic insults.

Not all preclinical studies of inhaled corticosteroids in experimentally induced lung injury and pneumonia resulted in improvement relative to placebo. For example, Sjoblom et al. randomized 16 rabbits into groups receiving inhalation of ammonia, followed by 30 -minute and 2 -hour delayed treatments with $0.5 \mathrm{mg}$ inhaled budesonide or placebo (48). The ammonia inhalation resulted in severe ALI after only 15 minutes. In comparison with placebo, budesonide did not result in improved gas exchange or reduced airway pressure levels during the observation period. This result may exemplify the limitations of delayed treatment with a relatively low dose of inhaled corticosteroid in the setting of a potent inciting injury. In addition, most of these studies involved models of sepsis or direct lung injury using an injurious agent and not a live microorganism model of pneumonia. The use of inhaled corticosteroids appears to decrease the injurious host response in the lung, but results cannot be directly extrapolated to infectious pneumonia where the benefits of a decreased host immune response may be attenuated by increased bacterial or viral replication.

\section{Role of Adjuvant Beta Agonists}

As previously described, pneumonia can increase vascular permeability resulting in loss of barrier function between the alveolar and vascular compartments. In experimental studies, beta agonists have demonstrated the ability to preserve pulmonary vascular stability and up-regulate alveolar fluid clearance. Spindler and Waschke compared effects of propranolol and epinephrine and concluded that activation of $\beta$-adrenergic receptor signaling contributes to the stability of endothelial barrier properties under baseline conditions (49). Therefore, beta agonists are likely to be most effective early in the course of developing lung injury when the alveolar epithelial and endothelial barriers are still relatively maintained. An extensive 
physiological review by Matthay et al. provides a detailed discussion of the experiments that have enhanced our understanding of the complex regulation of lung fluid balance by active transport mechanisms across both the alveolar and distal airway epithelium (50). Pertinent to this review, the authors commented on the potential beneficial effects of both beta agonists and corticosteroids on the reabsorption of edema from the distal airspaces of the lung, during physiological and pathological conditions.

There are only four trials looking at beta agonists and their ability to prevent ALI. The BALTI trial was the first trial to demonstrate that beta agonist therapy reduced extravascular lung water in patients with ALI/ARDS (51). However, 5 years later, the BALTI-2 trial using the same treatment regimen of intravenous salbutamol did not decrease mortality in ARDS patients and was stopped early due to safety concerns related to arrhythmias (52). Concurrently, the ALTA trial, which randomized patients with ALI to either $5 \mathrm{mg}$ of aerosolized albuterol or placebo every 4 hours for up to 10 days, was also stopped early for futility after finding no difference in ventilator free days and hospital mortality between the treatment groups (53). The ALTA trial did show that systemic absorption of aerosolized albuterol in patients with ALI/ARDS was sufficient based on measurements of plasma albuterol levels. A common factor of these negative trials was that the enrolled patients were already mechanically ventilated with established ARDS, so the therapeutic window for potential effects of beta agonist therapy might have been missed. The only RCT to test whether pretreatment with inhaled beta agonists might prevent ARDS was performed in patients undergoing elective esophagectomy in 12 centers in the United Kingdom (54). Although the treatment with salmeterol $100 \mu \mathrm{g}$ twice daily did not prevent the primary endpoint of early lung injury, the patients receiving salmeterol had lower pulmonary vascular permeability indices; lower serum levels of RAGE, TNF-alpha, and IL-1beta; and a lower incidence of postoperative pneumonia (7 vs. 17; OR 0.39; 95\% CI, 0.16-0.96) (54). While not specifically limited to patients with pneumo- nia, these studies are in patients with or at risk for developing ARDS with similar pathophysiology to patients with severe pneumonia suggesting that beta agonists may be beneficial as an adjuvant therapy in CAP, but future research is needed.

\section{Combined Use of Inhaled Corticosteroids and Beta Agonists}

There is a synergistic benefit of combined inhaled corticosteroid and beta agonists in patients with obstructive pulmonary disease. The bronchodilating effect of inhaled beta agonists may improve distal delivery of inhaled corticosteroids to the alveoli, while also increasing the efficacy of inhaled corticosteroids by increasing the nuclear localization of corticosteroid receptors (55). Both inhaled corticosteroids and beta agonists are medications broadly available, inexpensive, and with established safety profiles when used in combination.

In a recent multicenter RCT, the authors studied the effect of combined inhaled corticosteroid and beta agonist therapy in patients at high risk of developing ARDS, defined by a lung injury prediction score $\geq 4$ (56). Sixty patients were randomized to receive inhaled budesonide/formoterol versus placebo for up to 5 days. The primary outcome was change in oxygen saturation divided by the fraction of inspired oxygen (S/F) through day 5 . The patients at risk of ARDS randomized to receive inhaled budesonide/formoterol, compared to those receiving placebo, had improved oxygenation based on more rapid improvement in the S/F $(\mathrm{P}=0.02)$, with significant separation occurring at day 2. No patient in the treatment group had worsening S/F compared with eight patients (27\%) in the placebo group. This benefit appeared to be restricted to patients with pneumonia $(\mathrm{P}=0.03)$ versus those without pneumonia ( $\mathrm{P}=0.51)$ (56). Overall, patients in the treatment arm had lower rates of mechanical ventilation ( $53 \%$ vs. $21 \%, \mathrm{P}=0.01$ ) and ARDS ( $23 \%$ vs. $0 \%, \mathrm{P}=0.01$ ), as well as shorter hospital and ICU LOS. There was an imbalance in baseline severity of illness with more patients having baseline shock in the placebo group. However, shock was not associated with a change in S/F and 
did not modify the effect of treatment on S/F. The median time from presentation to the first dose of study drug was $<9$ hours in this study. If proven effective in the upcoming NIH-funded, 600-patient ARREST Pneumonia trial (NCT04193878), it is likely that early treatment is crucial to provide protective effects prior to the development of more severe lung injury.

These studies highlight the need for future research with inhaled therapies in pneumonia. Some trials using systemic corticosteroids have shown an increase in rates of hyperglycemia and/or increase in delayed complications, such as secondary infections. The use of short-term, inhaled corticosteroid therapy would not be expected to yield these complications. Further studies are needed to determine whether the combination of inhaled corticosteroids and beta agonists may provide additional benefit. The potential synergy between the anti-inflammatory effects of corticosteroids and increased capillary stability and edema resorption from beta agonists combined with timely inhaled delivery directly to the target organ prior to the onset of respiratory failure has the potential to maximize clinical benefit while limiting negative systemic side-effects.

\section{Discussion}

The consensus guidelines created by the Society of Critical Care Medicine and European Society of Intensive Care Medicine in 2017 recommended using corticosteroids for 5-7 days at a daily dose of $<400 \mathrm{mg}$ of intravenous hydrocortisone for all patients hospitalized with CAP. In this recommendation, they mention that patients with severe disease derived more benefit, but that all hospitalized CAP patients should be given corticosteroids (57). In contrast, the recent consensus guidelines for CAP by the Infectious Disease Society of America and American Thoracic Society (IDSA/ATS) published in 2019 did not recommend corticosteroids be used in patients with severe or non-severe CAP due to a lack of sufficient evidence (58). Clearly, additional clinical trials are needed to better define the patient populations that may benefit from the adjuvant use of corticosteroids, as well as to elucidate the ideal timing, route, dose, and duration of therapy. In summary, there may be a benefit for adjuvant corticosteroids in patients with severe CAP, but their role still needs to be better defined. Given the remaining equipoise for this important question despite multiple multicenter RCTs, future trials need to assess timely (early) delivery and discern which patients would benefit the most relative to their host characteristics, severity, and etiology of pneumonia, along with the best route of delivery, dose, and duration of therapy.

\section{Conclusion}

Despite conflicting guidelines, the strongest data currently supports using systemic corticosteroids for severe bacterial pneumonia. Using inhaled corticosteroids and beta-agonists has a theoretical benefit, but their exact role has yet to be determined.

What Is Already Known on this Topic

Adjuvant systemic corticosteroids may improve clinical outcomes in selected patients hospitalized with severe community-acquired bacterial pneumonia.

\section{What this Study Adds}

Proposed use of adjuvant inhaled corticosteroid therapy, with or without inhaled beta agonists, would theoretically not predispose patients to systemic adverse effects, and as such may be an attractive alternative to adjuvant use of systemic corticosteroids in patients with communityacquired pneumonia.

Authors' Contributions: Conception and design: SAH, JEL and EF; Acquisition, analysis and interpretation of data: $\mathrm{SAH}$, JEL and EF; Drafting the article SAH, JEL and EF; Revising it critically for important intellectual content: SAH, JEL and EF; Approved final version of the manuscript: SAH, JEL and EF.

Conflict of Interest: The authors declare that they have no conflict of interest.

\section{References}

1. Heron M. Deaths: Leading Causes for 2011. Natl Vital Stat Rep. 2015;64(7):1-96.

2. American Thoracic Society. Top 20 Pneumonia Facts 2015. [cited 2019 Nov 19]. Available from: https://www. thoracic.org/patients/patient-resources/resources/toppneumonia-facts.pdf, 
3. Ewig S, Ruiz M, Mensa J, Marcos MA, Martinez JA, Arancibia F, et al. Severe community-acquired pneumonia. Assessment of severity criteria. Am J Respir Crit Care Med. 1998;158(4):1102-8.

4. Rubenfeld GD, Caldwell E, Peabody E, Weaver J, Martin DP, Neff M, et al. Incidence and outcomes of acute lung injury. New Eng J Med. 2005;353(16):1685-93.

5. Valencia M, Badia JR, Cavalcanti M, Ferrer M, Agusti $\mathrm{C}$, Angrill J, et al. Pneumonia severity index class v patients with community-acquired pneumonia: characteristics, outcomes, and value of severity scores. Chest. 2007;132(2):515-22.

6. Feikin DR, Schuchat A, Kolczak M, Barrett NL, Harrison LH, Lefkowitz L, et al. Mortality from invasive pneumococcal pneumonia in the era of antibiotic resistance, 19951997. Am J Public Health. 2000;90(2):223-9.

7. Jain S, Self WH, Wunderink RG, Fakhran S, Balk R, Bramley AM, et al. Community-Acquired Pneumonia Requiring Hospitalization among U.S. Adults. New Eng J Med. 2015;373(5):415-27.

8. Mizgerd JP. Acute lower respiratory tract infection. New Eng J Med. 2008;358(7):716-27.

9. Kielgast F, Schmidt H, Braubach P, Winkelmann VE, Thompson KE, Frick M, et al. Glucocorticoids Regulate Tight Junction Permeability of Lung Epithelia by Modulating Claudin 8. Am J Respir Cell Mol Biol. 2016;54(5):70717.

10. Rittirsch D, Flierl MA, Ward PA. Harmful molecular mechanisms in sepsis. Nat Rev Immunol. 2008;8(10):77687.

11. Ware LB, Matthay MA. The acute respiratory distress syndrome. New Eng J Med. 2000;342(18):1334-49.

12. Meduri GU, Kanangat S, Bronze M, Patterson DR, Meduri CU, Pak C, et al. Effects of methylprednisolone on intracellular bacterial growth. Clin Diag Lab Immunol. 2001;8(6):1156-63.

13. Li Y, Cui X, Li X, Solomon SB, Danner RL, Banks SM, et al. Risk of death does not alter the efficacy of hydrocortisone therapy in a mouse E. coli pneumonia model. Intensive Care Med. 2008;34(3):568-77.

14. Sibila O, Luna CM, Agustí C, Baquero S, Gando S, Patrón JR, et al. Effects of glucocorticoids in ventilated piglets with severe pneumonia. Eur Respir J. 2008;32(4):1037-46.

15. Marik P, Kraus P, Sribante J, Havlik I, Lipman J, Johnson DW. Hydrocortisone and Tumor Necrosis Factor in Severe Community-Acquired Pneumonia: A Randomized Controlled Study. Chest. 1993;104(2):389-92.

16. Monton C, Ewig S, Torres A, El-Ebiary M, Filella X, Rano A, et al. Role of glucocorticoids on inflammatory response in nonimmunosuppressed patients with pneumonia: a pilot study. Eur Respir J. 1999;14(1):218-20.

17. Confalonieri M, Urbino R, Potena A, Piattella M, Parigi P, Puccio G, et al. Hydrocortisone Infusion for Severe Com- munity-acquired Pneumonia. Am J Respir Crit Care Med. 2005;171(3):242-8.

18. Fernández-Serrano S, Dorca J, Garcia-Vidal C, Fernández-Sabé N, Carratalà J, Fernández-Agüera A, Corominas $M$, et al. Effect of corticosteroids on the clinical course of community-acquired pneumonia: a randomized controlled trial. Crit Care. 2011;15(2):R96.

19. Meijvis SCA, Hardeman H, Remmelts HHF, Heijligenberg R, Rijkers GT, van Velzen-Blad H, et al. Dexamethasone and length of hospital stay in patients with community-acquired pneumonia: a randomised, double-blind, placebo-controlled trial. Lancet. 2011;377(9782):2023-30.

20. Blum CA, Nigro N, Briel M, Schuetz P, Ullmer E, SuterWidmer I, et al. Adjunct prednisone therapy for patients with community-acquired pneumonia: a multicentre, double-blind, randomised, placebo-controlled trial. Lancet. 2015;385(9977):1511-8.

21. Torres A, Sibila O, Ferrer M, Polverino E, Menendez R, Mensa J, et al. Effect of corticosteroids on treatment failure among hospitalized patients with severe communityacquired pneumonia and high inflammatory response: a randomized clinical trial. Jama. 2015;313(7): 677-86.

22. Snijders D, Daniels JM, de Graaff CS, van der Werf TS, Boersma WG. Efficacy of corticosteroids in communityacquired pneumonia: a randomized double-blinded clinical trial. Am J Respir Crit Care Med. 2010;181(9):975-82.

23. Salih W, Schembri S, Chalmers JD. Simplification of the IDSA/ATS criteria for severe CAP using meta-analysis and observational data. Eur Respir J. 2014;43(3):842-51.

24. Lloyd M, Karahalios A, Janus E, Skinner EH, Haines T, De Silva A, et al. Effectiveness of a Bundled Intervention Including Adjunctive Corticosteroids on Outcomes of Hospitalized Patients With Community-Acquired Pneumonia: A Stepped-Wedge Randomized Clinical Trial. JAMA Intern Med. 2019;179(8):1052-60.

25. Jensen AV, Egelund GB, Andersen SB, Petersen PT, Benfield T, Witzenrath $\mathrm{M}$, et al. The Glycemic Gap and 90-Day Mortality in Community-acquired Pneumonia: A Prospective Cohort Study. Ann Am Thorac Soc. 2019;16(12):1518-26.

26. Jensen AV, Egelund GB, Andersen SB, Trier Petersen P, Benfield T, Faurholt-Jepsen D, et al. The impact of blood glucose on community-acquired pneumonia: a retrospective cohort study. Eur Respir J Open Res. 2017;3(2):0011402016 .

27. McAlister FA, Majumdar SR, Blitz S, Rowe BH, Romney J, Marrie TJ. The Relation Between Hyperglycemia and Outcomes in 2,471 Patients Admitted to the Hospital With Community-Acquired Pneumonia. Diabetes Care. 2005;28(4):810-5.

28. Waljee AK, Rogers MAM, Lin P, Singal AG, Stein JD, Marks RM, et al. Short term use of oral corticosteroids and related harms among adults in the United States: population based cohort study. BMJ. 2017;357:j1415. 
29. Iwashyna TJ, Burke JF, Sussman JB, Prescott HC, Hayward RA, Angus DC. Implications of Heterogeneity of Treatment Effect for Reporting and Analysis of Randomized Trials in Critical Care. Am J Respir Crit Care Med. 2015;192(9):1045-51.

30. Siemieniuk RA, Meade MO, Alonso-Coello P, Briel M, Evaniew N, Prasad M, et al. Corticosteroid therapy for patients hospitalized with community-acquired pneumonia: A systematic review and meta-analysis. Ann Intern Med. 2015;163(7):519-28.

31. Wirz SA, Blum CA, Schuetz P, Albrich WC, Noppen C, Mueller B, et al. Pathogen- and antibiotic-specific effects of prednisone in community-acquired pneumonia. Eur Respir J. 2016;48(4):1150-9.

32. Stern A, Skalsky K, Avni T, Carrara E, Leibovici L, Paul M. Corticosteroids for pneumonia. Cochrane Database Syst Rev. 2017;12(12):CD007720.

33. Briel M, Spoorenberg SMC, Snijders D, Torres A, Fernandez-Serrano S, Meduri GU, et al. Corticosteroids in Patients Hospitalized With Community-Acquired Pneumonia: Systematic Review and Individual Patient Data Metaanalysis. Clin Infect Dis. 2017;66(3):346-54.

34. Huang J, Guo J, Li H, Huang W, Zhang T. Efficacy and safety of adjunctive corticosteroids therapy for patients with severe community-acquired pneumonia: A systematic review and meta-analysis. Medicine. 2019;98(13):e14636.

35. Wan Y-D, Sun T-W, Liu Z-Q, Zhang S-G, Wang L-X, Kan Q-C. Efficacy and Safety of Corticosteroids for Community-Acquired Pneumonia: A Systematic Review and Meta-Analysis. Chest. 2016;149(1):209-19.

36. Wu W-F, Fang Q, He G-J. Efficacy of corticosteroid treatment for severe community-acquired pneumonia: A meta-analysis. Am J Emerg Med. 2018;36(2):179-84.

37. Rodrigo C, Leonardi-Bee J, Nguyen-Van-Tam J, Lim WS. Corticosteroids as adjunctive therapy in the treatment of influenza. Cochrane Database Syst Rev. 2016;3:CD010406.

38. Moreno G, Rodríguez A, Reyes LF, Gomez J, Sole-Violan J, Díaz E, et al. Corticosteroid treatment in critically ill patients with severe influenza pneumonia: a propensity score matching study. Intensive Care Med. 2018;44(9):1470-82.

39. Ni Y-N, Chen G, Sun J, Liang B-M, Liang Z-A. The effect of corticosteroids on mortality of patients with influenza pneumonia: a systematic review and meta-analysis. Crit Care. 2019;23(1):99.

40. Merckx J, Wali R, Schiller I, Caya C, Gore GC, Chartrand $\mathrm{C}$, et al. Diagnostic accuracy of novel and traditional rapid tests for influenza infection compared with reverse transcriptase polymerase chain reaction. Ann Intern Med. 2017;167(6):395-409.

41. Bartko J, Stiebellehner L, Derhaschnig U, Schoergenhofer C, Schwameis M, Prosch H, et al. Dissociation between systemic and pulmonary anti-inflammatory effects of dexamethasone in humans. Brit J Clin Pharm. 2016;81(5):865-77.
42. Festic E, Scanlon PD. Incident pneumonia and mortality in patients with chronic obstructive pulmonary disease. A double effect of inhaled corticosteroids? Am J Respir Crit Care Med. 2015;191(2):141-8.

43. Kew KM, Seniukovich A. Inhaled steroids and risk of pneumonia for chronic obstructive pulmonary disease. Cochrane Database Sys Rev. 2014;3:CD010115.

44. Walther S, Jansson I, Berg S, Olsson Rex L, Lennquist S. Corticosteroid by aerosol in septic pigs - effects on pulmonary function and oxygen transport. Intensive Care Med. 1993;19(3):155-60.

45. Forsgren PE, Modig JA, Dahlbäck CM, Axelsson BI. Prophylactic treatment with an aerosolized corticosteroid liposome in a porcine model of early ARDS induced by endotoxaemia. Acta Chir Scand. 1990;156(6-7):423-31.

46. Jansson AH, Eriksson C, Wang X. Effects of budesonide and $\mathrm{N}$-acetylcysteine on acute lung hyperinflation, inflammation and injury in rats. Vascul Pharm. 2005;43(2):10111.

47. Wang J, Zhang L, Walther SM. Inhaled budesonide in experimental chlorine gas lung injury: influence of time interval between injury and treatment. Intensive Care Med. 2002;28(3):352-7.

48. Sjöblom E, Höjer J, Kulling PE, Stauffer K, Suneson A, Ludwigs U. A placebo-controlled experimental study of steroid inhalation therapy in ammonia-induced lung injury. J Toxicol Clin Toxicol. 1999;37(1):59-67.

49. Spindler V, Waschke J. B-Adrenergic stimulation contributes to maintenance of endothelial barrier functions under resting conditions. FASEB J. 2010;24:1_supp:777.4.

50. Matthay MA, Folkesson HG, Clerici C. Lung epithelial fluid transport and the resolution of pulmonary edema. Phys Rev. 2002;82(3):569-600.

51. Perkins GD, McAuley DF, Thickett DR, Gao F. The betaagonist lung injury trial (BALTI): a randomized placebo-controlled clinical trial. Am J Respir Crit Care Med. 2006;173(3):281-7.

52. Gates S PG, Lamb S, Kelly C, Thickett D, Young D, McAuley $\mathrm{D}$, et al. Beta-Agonist Lung Injury Trial-2 (BALTI-2): a multicentre, randomised, double-blind, placebo-controlled trial and economic evaluation of intravenous infusion of salbutamol versus placebo in patients with acute respiratory distress syndrome. Health Technol Assess. 2013;17(38):v-vi, 1-87.

53. National Heart, Lung, and Blood Institute Acute Respiratory Distress Syndrome (ARDS) Clinical Trials Network, Matthay MA, Brower RG, Carson S, Douglas IS, Eisner M, et al. Randomized, placebo-controlled clinical trial of an aerosolized $\beta_{2}$-agonist for treatment of acute lung injury. Am J Respir Crit Care Med. 2011;184(5):561-8.

54. Perkins GD, Gates S, Park D, Gao F, Knox C, Holloway $\mathrm{B}$, et al. The beta agonist lung injury trial prevention. A randomized controlled trial. Am J Respir Crit Care Med. 2014;189(6):674-83. 
55. Barnes PJ. Scientific rationale for inhaled combination therapy with long-acting beta2-agonists and corticosteroids. Eur Respir J. 2002;19(1):182-91.

56. Festic E, Carr GE, Cartin-Ceba R, Hinds RF, BannerGoodspeed V, Bansal V, et al. Randomized Clinical Trial of a Combination of an Inhaled Corticosteroid and Beta Agonist in Patients at Risk of Developing the Acute Respiratory Distress Syndrome. Critical Care Med. 2017;45(5):798-805.

57. Pastores SM, Annane D, Rochwerg B; Corticosteroid Guideline Task Force of SCCM and ESICM. Guidelines for the diagnosis and management of critical illness-related corticosteroid insufficiency (CIRCI) in critically ill patients (Part II): Society of Critical Care Medicine (SCCM) and European Society of Intensive Care Medicine (ESICM) 2017. Intensive Care Med. 2018;44(4):474-7.

58. Metlay JP, Waterer GW, Long AC, Anzueto A, Brozek J, Crothers K, et al. Diagnosis and Treatment of Adults with Community-acquired Pneumonia. An Official Clinical Practice Guideline of the American Thoracic Society and Infectious Diseases Society of America. Am J Respir Crit Care Med. 2019;200(7):e45-67. 